\title{
On the English Translation Strategy of Science Fiction from Humboldt's Linguistic Worldview - Taking the English Translation of Three-Body Problem as an Example
}

\author{
Jiali Gao \\ College of Foreign Languages, University of Shanghai for Science and Technology, Shanghai, China \\ Yan Hua \\ College of Foreign Languages, University of Shanghai for Science and Technology, Shanghai, China
}

\begin{abstract}
In recent years, many science fictions have been published, such as The Three-body Problem, The Wandering Earth, and so on. The number of people who are interested in science fiction is increasing. Meanwhile, the translation of science fiction has become more important. The Linguistic Worldview proposed by Humboldt is of great importance to the translation of science fiction. This thesis is based on Linguistic Worldview. It analyzes The Three-body Problem (English version) and the importance of such theory to the translation of science fiction. It proposes three translation strategies: free translation, literal translation, and transcreation.
\end{abstract}

Index Terms - science fiction, the linguistic worldview, translation strategy

\section{INTRODUCTION}

Science fiction, originated in the modern West, is created by authors with reasonable assumptions on the premise of respecting the laws of science. ${ }^{[1]}$ In recent years, with the publication of novels such as The Three-Body Problem, Wandering Earth, Folding Beijing, and so on, science fiction has become increasingly popular among readers. At the same time, the translation of science fiction has become a major focus for scholars to explore.

Based on previous studies, the focuses can be divided into three parts: translation and introduction, translation theory, and translation strategies. In terms of translation, Qian Jiang (2006) investigates the translation and acceptance of science fiction in the 20th century in China, analyzes typical texts, and reveals the factors in different historical periods that affect the translation and acceptance of science fiction. Fangyu Lin (2019) also focuses on the translation and introduction and makes an analysis of the foreign translation of contemporary Chinese science fiction based on the communication theory.

Discussions on the translation theory and translation strategies are the main points of these studies. Ting Zeng (2012) analyzes the problems and current situation of science fiction translation and studies the translation of science fiction from the perspective of reception theory. She believes that domestication should be the main method, foreignization should be the auxiliary method, and the meaning of the original text should be faithfully translated. Jieya Kang (2014), guided by Toury's theory of translation norms, investigates the translation and introduction of science fiction in the late Qing Dynasty and analyzes the translation norms followed by translators in the late Qing Dynasty in the process of science fiction translation. According to the functional equivalence theory, Tao Sheng (2016) analyzes text translation from the perspectives of cultural default and linguistic heterogeneity, interpretive texts, and humor, and discusses the guiding significance of this theory to the translation of science fiction.

As for the translation strategy, Hao Xu (2019) analyzes the translation strategies of cultural words in The Three-body Problem and finds that the translator used footnotes or in-text annotations to explain cultural words and provide readers with background information. Xueting Song (2020) takes the English translation of The Three-body Problem as an example to study the translation of new words in science fiction and proposes four translation strategies: literal translation, free translation, transliteration, and addition. From the perspective of Newmark's translation theory, Jiadi Lei (2020) explores the translation strategies of scientific terms, proper nouns, neologisms, slang, and colloquialisms in science fiction.

There are many studies on Humboldt's linguistic worldview, but few on translation. Most of the previous studies have focused on Humboldt's linguistic world view and his view of translation.

Jinqin Li (2006) talks about Humboldt's linguistic world view, analyzes the translatability and untranslatability in the process of translation. She believes that the relationship between them should be treated dialectically. From the perspective of cognitive linguistics, Zhifeng Xuan (2014) further proposes that translation is a transformation of the 
world view. Yili Fang (2020) analyzes why Humboldt regarded language and translation as a powerful force controlling the history of human development from the perspective of historical reconstruction and proposes that there was an internal connection between Humboldt's linguistic worldview and his view of translation. There is also a lack of research on translation strategies. Jimei Gu (2016) discusses the guiding role of Humboldt's view of language and translation in the English translation of Chinese classics and believes that it can help to establish standards for the English translation of Chinese classics.

The research on Humboldt's language worldview on translation strategies is quite a few and the previous studies didn't involve specific literary genres. Science fiction literature is a hot topic and many scholars have studied its translation. However, no one has ever studied it from Humboldt's linguistic worldview, so this paper will explore the guiding significance of Humboldt's linguistic worldview to the translation of science fiction.

\section{TRANSLATION STANDARDS OF SCIENCE FICTION}

Unlike ordinary literary genres, science fiction involves both scientific and technological knowledge and literariness, which makes it a challenge for translators. Based on his years of experience in science fiction translation, Guo Jianzhong has concluded the translation criteria of science fiction, namely, literariness, scientificity, and popularity. ${ }^{[5]}$

Firstly, as literary work, science fiction should contain literariness, which should be reflected in the description of characters, environment, psychological activities, etc. ${ }^{[6]}$ We cannot simply regard it as a scientific article. As its name implies, "science fiction" itself combines "science" with "fantasy" and has a strong personal style. Therefore, translators should fully reflect the style of the original text in the process of translation, instead of translating word for word.

Secondly, as stated in its definition, science fiction needs to abide by scientific conclusions, that is, they need to be scientific. No matter how fanciful the author is, the world he creates must be based on scientific laws. Otherwise, it will violate the requirements of science fiction. Translators should particularly pay attention to the accuracy of terminology translation and ensure that the text is well-knit and logical.

Finally, as a branch of popular fiction, science fiction should also be popular. The translation is a multilingual interaction, and it is sometimes difficult for us to cover all bases. Different cultural backgrounds and logical thinking will bring challenges to translators. ${ }^{[8]}$ What the translators should do is to communicate the content of the original text to the target readers as much as possible and help the readers to understand it in an easy-to-understand way.

\section{HUMBOLDT'S LINGUISTIC WORLDVIEW}

The core idea of Humboldt's linguistic worldview is that each language contains a special worldview. Language differences are not only reflected in different symbols, but also different worldviews. In this regard, Humboldt made a further explanation, namely, language is "one" and "many", the national character of language and the creativity in language.

As for the statement that language is "one" and "many", Humboldt believes that there is only one language in the world, or that everyone has a special language. These two views seem contradictory. People of different races and countries use different languages; people of the same ethnic group use the same language. However, in fact, Humboldt's view has been out of the normal ideological dimension. "There is only one language in the world." Here "language" means the way people communicate with each other, not specific languages. As for "everyone has a special language", Humboldt explains that although people of the same ethnic group use the same language, they also have their own characteristics due to their different logical thinking. This reflects the universality and particularity of language.

As far as nationality is concerned, the language of one nation can show its unique spirit and thoughts to other nations. The spirit of the nation represents the language of the nation, and conversely, the language of the nation is also the concentrated embodiment of the spirit of the nation. Every nation has its own unique language, which is characterized by its own culture and form. It is very difficult to find the exact equivalent words between the two languages. The difference between languages can therefore be understood as the difference between worldviews, and the process of translation can be said to be the collision between different worldviews. ${ }^{[4]}$ People who grow up in different linguistic and cultural backgrounds have different logical thinking and hold different worldviews.

Finally, Humboldt talked about the creativity of language. In his opinion, language is the voice of human beings expressing their thoughts, and we should not limit it to words in oral or written form, but the whole speech activity. The creativity of language is embodied in this process, which reflects the idea that human beings have unlimited thinking. Although the rules of language are limited, human beings can make unlimited use of them. In Humboldt's opinion, human beings are generally capable of word-formation, and this creativity can be divided into regular creation and irregular creation according to whether it depends on previous experience and rules or not. It is this creativity that makes translations between languages translatable.

\section{TRANSLATION STRATEGIES OF SCIENCE FiCTION}

Based on the features of science fiction and Humboldt's linguistic worldview, this paper will put forward three translation strategies, namely free translation, literal translation and transcreation. 


\section{A. Free Translation}

As literary work, we need to consider many factors in the translation of science fiction, one of which is cultural differences. As Humboldt mentioned above, each language has its own national characters, so it is not advisable to translate word by word. ${ }^{[2]}$ We need to understand that it's hard to find a perfect equivalent in another language. Besides, considering that science fiction also belongs to popular fiction, it is necessary to make the translation easy to understand and maintain the balance between popularity and literariness. This requires translators to have a correct understanding of the text first, and then to translate and facilitate the target audience to understand.

This paper will take the English translation of The Three-Body Problem as an example. Although the novel itself belongs to science fiction, the description of the Cultural Revolution period in the novel also takes up a lot of space, so there are a lot of words with Chinese culture, which need to be correctly understood by translators and cannot be rigidly translated word by word.

Example 1: “......, 他有奶便是娘, ......! ”

Translation: “....... He would serve any master who dangled money in front of him......”

Analysis: This is a Chinese saying, which refers to a person who is cynical about profits and will help whoever gives him the benefit. However, in the process of translation, if we choose the literal translation, we will ignore the cultural background of the target readers, who may not know the meaning of this sentence at all. Instead, the translator chose to translate it into the phrase "serve any master who dangled money in front of him," which is easy for the reader to understand without changing the meaning of the text.

Example 2: 对于你这种政治案件, 现在公检法系统都是宁左勿右, 左是方法问题, 右是路线问题, 最终大方 向还是要军管会定。

Translation: "Now, faced with political cases like yours, all prosecutorial organs and courts would rather be too severe than too lax. This is because treating you too severely would just be a mistake in method, but treating you too laxly would be a mistake in political direction. Ultimately, however, the decision belongs to the military control commission."

Analysis: This sentence seems simple, but if you read it carefully, you will find that the words “左” and “右” here are not easy to translate. In politics, “左” means "radical" and “右” means “conservative”. Here we can translate “左” into "treating ... too severely" and "right" into "treating ... too laxly". If the translator regards it as location or orientation, the translation will greatly deviate from the original meaning.

Example 3: “......我说你不成吧, 你还硬充六根脚指头。”

Translation: "Finding it hard to bear? I said you couldn't handle it. And you insisted on playing the tough guy."

Analysis: The phrase “硬充六根脚指头” is an old saying, which means to pretend to know something. If the translator chooses the literal translation of this idiom, it will be difficult for the target audience to understand, because there is no such expression in their culture. Therefore, in the process of translation, the translator can choose the expression which is similar to the meaning in the target language, or, as in the translation, choose the expression that the reader can understand.

Example 4: 这样，叶文洁的成果和论文最终都被他占去，他也成了部队政工干部中又红又专的典型。

Translation: Thus, he could take credit for all of Ye's research results and papers, and cast himself as an exemplary political officer with both technical acumen and revolutionary zeal.

Analysis: The word “又红又专” in the sentence is also a word with Chinese cultural characteristics, which refers to the need to master professional knowledge and technology, but also to firm the position of the proletariat. The word “红” has a special meaning in Chinese culture, and it is even a cultural totem of Chinese people. When translating Chinese literary works, translators should pay attention to the meaning it represents according to the specific context.

Example 5: “......咱们再好好谈谈, 解开你的思想疮㾂。”

Translation: “...Then we can have a good heart-to-heart and resolve your ideological difficulties.”

Analysis: In this sentence, the translation of the phrase “思想疙㾂” may be a difficulty. The term “疙瘩” originally refers to the protrusion on the skin, but this is clearly not what it means in this sentence. If we simply translate it as “pimple”, the reader may have no idea what this means. The phrase “思想疮㾂” is common in Chinese political texts, and generally refers to people's ideological problems. Therefore, translators shall translate it as "ideological difficulties", which is more likely to be accepted by target readers.

\section{B. Literal Translation}

Although there is a lot of dummy content in science fiction, they are not completely ridiculous thoughts but recreated under the premise of respecting the laws of science. There are also many scientific terms in novels. For such words, we often choose literal translation to ensure the accuracy of terms. Science fiction needs to be scientific, so translators need to carefully consider the translation of these scientific terms to ensure that the articles are well-knit and congenial with scientific knowledge. ${ }^{[3]}$

In the Three-Body Problem, there are a lot of terms about astrophysics, and translator often chooses literal translation, which is also a relatively official translation. For example, “球状闪电” is translated into “ball lightning”; “例子碰撞” is 
translated into “particles Colliding”; “抛物面天线” is translated into "parabolic antenna”; “量子波函数” is translated into “Quantum wave function”; “高能加速器” is translated into "high-energy particle accelerator”; “超弦模型” is translated into "superstring model”; “宇宙背景辐射” is translated into “cosmic microwave background”; “多普勒效 应" is translated into "Doppler effect" and so on.

In addition to scientific terms, Chinese novels also have a lot of words with Chinese cultural characteristics. As mentioned above, we can choose the free translation, but free translation is not always conducive to the output of culture ${ }^{[7]}$ Some words even do not need free translation so that the target readers can understand them. Translators can try to use literal translation and add annotations when necessary to provide as much background information as possible so that readers can understand the meaning. Such translations are also more faithful to the original text and readers can understand the different cultural atmosphere.

In the Three-Body problem, the hero Wang Miao has several experiences playing the three-body games. Each time he enters the game, he will meet some people from a particular period, and “周文王” and “纣王” are two of them. “周文 王” and “纣王” were Chinese historical figures, but they both had similar names of "Zhou". Therefore, translators need to pay attention to the translation of their names, otherwise, it would confuse readers. The translator chooses the literal translation and adds some necessary information. “周文王” is translated into “King Wen of Zhou” and “纣王” is translated into "King Zhou of Shang", which is clear to the readers.

The Three-Body Problem makes an introduction to Ye Wenjie's past, which is based on the cultural Revolution and contains many words from the cultural background of that time. For example, the “五七干校” was established during the Cultural Revolution to implement Mao's May 7 Directive, and the term “五七” in this term is also the date when the directive was given. Therefore, the translation of this word is "May Seventh Cadre Schools". Although free translation is not used, readers still can understand the meaning of this word. “红卫兵” was also a mass organization founded by students during the Cultural Revolution. The translation of “红” does not have a special meaning as mentioned above, because the members of this organization will wear red armbands, so it is directly understood as "Red" here. Another example is the “批斗会” and its translation is "Struggle session”. To facilitate readers' reading, the translator adds annotations at the end. In this way, readers can have a correct understanding of the nature of such meetings and know the hardship that people have experienced in the Cultural Revolution.

\section{Transcreation}

As a science fiction novel, The Three-body Problem also has a lot of new words. As for these words, the translator will encounter some challenges in the process of translation. For some words, we can choose to use literal translation or free translation, but in some cases, these methods may not work. Translators sometimes find it difficult to find a suitable expression in the target language for the content invented by the author, and this method may help us to solve these problems.

Humboldt's linguistic worldview also talks about it. The creativity of language reflects the idea that human beings have unlimited thinking. Although the rules of language are limited, human beings can make unlimited use of them. This creativity can be divided into regular creation and irregular creation according to whether it depends on previous experience and rules or not. Therefore, we can get two translation methods: word-formation based on existing words and derivation.

There is plenty of dummy content in this book, such as “飞星不动”, which means that all-stars in a trisolaran galaxy are in a relatively static crossing line. It is the worst omen in a trisolaran world. The translator chose the existing English words and translated them into "a frozen flying star", an unusual but concise and vivid expression that enables the reader to understand the specific meaning of the phenomenon. In this book, the author introduced a theory, which means that contact with an alien civilization is just a switch or symbol. Therefore, the translator translated it into “contact as symbol theory", which summarizes the content of this theory in just four words. The words “乱纪元” and “恒纪元” also run through the whole trisolaran world, both of which are based on the trisolaran movement. The difference between “乱” and “恒” lies in whether the turnover of day and night caused by the trisolaran movement is orderly. Therefore, the translator chooses "chaotic" and "stable" to describe the two periods, which are concise and clear.

Most of the dummy content in The Three-body problem is related to the trisolaran movement, so there are a large number of words related to "three”, such as “三日凌空”, “三日连珠”, etc., which we cannot find equivalents in English. If the translator chooses to introduce the whole meaning of these words, it will be a little verbose and will not read smoothly. Therefore, when translating these words, we can choose derivation. The prefix "tri-" means "three". So we can translate “三日凌空” into “tri-solar days”; “三日连珠” into “tri-solar syzygy”; “三体人” into "trisolaran”.

Another example is the concept proposed by the author: “智子”, the intelligent microscopic particles generated by protons after two-dimensional expansion and modification. When translating the word, we tend to think of particles such as protons and neutrons, all of which have the suffix "-on", so this can also be taken into account in the translation of “智子”. As for the prefix, the translator chose "soph-", an affix that means "intelligence". Therefore, “智子” is translated into "sophon", its structure accords with the way of word formation in English and its meaning is consistent 
with the original text.

\section{CONCLUSION}

Among all genres of literary works, there are relatively few translations of science fiction. In terms of quantity, there are more English-Chinese translations, while fewer Chinese-English translations. In recent years, with the publication of a lot of science fiction, the researches on science fiction translation are also on the rise. Therefore, this paper, guided by Humboldt's linguistic worldview and taking the English translation of The Three-Body Problem as an example, hopes to contribute to the English translation strategy of science fiction. This paper analyzes the English translation of The Three-Body Problem and puts forward three translation strategies, namely free translation, literal translation and transcreation.

Of course, such translation strategies may have some limitations and not be professional enough. However, the creation and translation of science fiction are complementary. With the continuous development of science fiction in China, our translation of such literary genre can also be improved.

\section{REFERENCES}

[1] Haowen Liang. (2019). Foreign Translation of Chinese Contemporary Science Fiction and Its Review. Journal of Guangdong University of Foreign Studies, 30(1): 41-47.

[2] Jimei Gu. (2016). Humboldt's Views on Language, Translation and English Translation of Classics. Journal of Suzhou University of Science and Technology, 33(2): 97-102.

[3] Jianghua Qin, Wenhua Zeng. (2010). Humboldt's View on Translation and its Enlightenment to the English Translation of Classics. Journal of University of Electronic Science and Technology of China, 12(4): 77-81.

[4] Wenqiao Xiu, Tianyang Jiang. (2018). Translation of Science Fiction from the Perspective of Language Culture-Communication--A Case study of Liu Kun's Translation of Folding Beijing. Chinese Science and Technology Translators Journal, 31(1): 46-49.

[5] Xiaofeng Wang. (2013). Research on Translation Thought and Practice by Guo Jianzhong. Shanghai: Shanghai International Studies University.

[6] Yang Liu. (2016). Literary Translation Skills of Science fiction -- Taking Tomorrowland as an example. English Square, 6(4):24-25.

[7] Zhifeng Xuan. (2014). "Translation is the Transformation of worldview" on cognitive Linguistics. Journal of Shangqiu Normal University, 30(2): 124-130.

[8] Zhongwei Chen. (2020). On the Realization of Fidelity in Science fiction Translation -- A Case study of the English translation of Wandering Earth. Overseas English, 21(8): 14-16.

Jiali Gao was born in Jiangsu Province, China. She is currently a postgraduate in the College of Foreign Languages, University of Shanghai for Science and Technology, Shanghai, China. Her major is English Translation.

Yan Hua graduated from University of Shanghai for Science and Technology (USST) in 1996. She is currently an associate professor at USST. Her research interests mainly are Australian Literature and Teaching Methodology. 